\title{
The upper mantle beneath the South Atlantic Ocean, South America and Africa from waveform tomography with massive data sets
}

\author{
NICOLAS LUCA CELLI ${ }^{1}$, SERGEI LEBEDEV ${ }^{1}$, ANDREW \\ J. SCHAEFFER ${ }^{2}$, MATTEO RAVENNA ${ }^{3}$ AND CARMEN \\ GAINA $^{4}$ \\ ${ }^{1}$ Dublin Institute for Advanced Studies \\ ${ }^{2}$ Geological Survey of Canada, Pacific Division, Sidney \\ Subdivision, Natural Resources Canada \\ ${ }^{3}$ Dublin Institute for Advanced studies, now at P-LAB Srl \\ ${ }^{4}$ Centre for Earth Evolution and Dynamics (CEED), University \\ of Oslo \\ Presenting Author: nlscelli@gmail.com
}

The South Atlantic Ocean and the surrounding continents of Africa and South America share 135 million years of geological history since the breakup of western Gondwana. The structure of the mantle and crust beneath the region is however highly debated, with little agreement on the number and shape of the many hotspots in the South Atlantic, the extent of the cratonic cores of the continents around it, and the structure of the Andean Subduction Zone. The debate is largely driven by the differences in the few seismic tomography models of the mantle underneath, which are challenged by the lack of seismic stations in the whole region, and particularly within the oceanic region. In order to tackle this issue, we gathered a massive dataset of over 1.2 million waveform fits, including all recently available data in the region, that we inverted using waveform tomography to produce a new, S-wave model of the crust, upper mantle and transition zone beneath the study area. The resulting model SA2019 is computed using an efficient multimode waveform inversion scheme that allows us to extract structural information from millions of seismograms and jointly invert them for the $3 \mathrm{D}$ distribution of S-wave velocity and azimuthal anisotropy. In Africa and South America, our new tomographic images reveal that the Amazon-, West African-, Congo- and Tanzanian cratons are much more complex and fragmented than previously proposed, with new, separate lithospheric units within some of the previously proposed cratonic boundaries. Additionally, we image the structure of the Paranapanema, Parnaiba blocks in South America and propose boundaries for the Niassa- and the newly proposed Cubango craton in Africa, all unexposed at the surface. In the South Atlantic Ocean, SA2019 reveals the patterns of interaction between the Mid-Atlantic Ridge (MAR) and the nearby hotspots, where broad, low-velocity anomalies extend substantially deeper into the upper mantle. By subtracting the seismic signature of the global average spreading oceanic lithosphere from local, basin-scale averages, we can better image the vertical structure of the low velocities beneath the Tristan da Cunha, Vema and Trindade hotspots, brought into focus by strong, local variations in the lithospheric cooling. 